\title{
Global Systems Science and Policy
}

\author{
Ralph Dum and Jeffrey Johnson
}

\begin{abstract}
The vision of Global Systems Science (GSS) is to provide scientific evidence and means to engage into a reflective dialogue to support policy-making and public action and to enable civil society to collectively engage in societal action in response to global challenges like climate change, urbanisation, or social inclusion. GSS has four elements: policy and its implementation, the science of complex systems, policy informatics, and citizen engagement. It aims to give policy makers and citizens a better understanding of the possible behaviours of complex social systems. Policy informatics helps generate and evaluate policy options with computer-based tools and the abundance of data available today. The results they generate are made accessible to everybody_policy makers, citizens — through intuitive user interfaces, animations, visual analytics, gaming, social media, and so on. Examples of Global Systems include epidemics, finance, cities, the Internet, trade systems and more. GSS addresses the question of policies having desirable outcomes, not necessarily optimal outcomes. The underpinning idea of GSS is not to precisely predict but to establish possible and desirable futures and their likelihood. Solving policy problems is a process, often needing the requirements, constraints, and lines of action to be revisited and modified, until the problem is 'satisficed', i.e. an acceptable compromise is found between competing objectives and constraints. Thus policy problems and their solutions coevolve much as in a design process. Policy and societal action is as much about attempts to understand objective facts as it is about the narratives that guide our actions. GSS tries to reconcile these apparently contradictory modes of operations. GSS thus provides policy makers and society guidance on their course of action rather than proposing (illusionary) optimal solutions.
\end{abstract}

R. Dum

The European Commission, 25 avenue de Beaulieu, 1160 Brussels, Belgium

J. Johnson $(\bowtie)$

Faculty of Science, Technology, Engineering and Mathematics, The Open University,

Milton Keynes, UK

e-mail: jeff.johnson@open.ac.uk

J. Johnson et al. (eds.), Non-Equilibrium Social Science and Policy, Understanding Complex Systems, DOI 10.1007/978-3-319-42424-8_14 


\section{Introduction}

The vision of Global Systems Science (GSS) is to provide scientific evidence to support policy-making, public action and to enable civil society to collectively engage in societal action [14].

Policy makers suffer from an intrinsic difficulty when addressing challenges such as climate change, financial crises, pandemics, or energy sufficiency since the impact and unintended consequences of public policy action are increasingly hard to anticipate. Such challenges are global and connect policies across different sectors. Faced with such highly interconnected challenges, societies still tend to address isolated subsystems and so fail to achieve systemic change. GSS can drive change by

- helping develop an integrated policy perspective on global challenges; and

- developing a research agenda to tackle the fundamental research challenges.

Societies are complex multilevel socio-technical systems. Social, economic, political and technical problems occur at all levels, and they interact between local and global levels. No single discipline can address these problems. Instead they require integrating within the new transdisciplinary science of complex systems.

By itself science will not solve the problems of policy unless there are ways to establish a dialogue between science and the players in policy, including policy makers and citizens. Although some policy makers and citizens have high levels of scientific knowledge, it is not easy to reconcile the need to implement policies aligned to scientific facts. First, scientific facts are rarely formulated in ways that help stakeholders to use them in a given decision and, often due to their probabilistic nature, scientific facts rarely point unambiguously in one direction towards a decision. GSS attempts to address this issue through policy informatics, i.e. data and informatics tools that policy makers and citizens can use in practical ways. Second, not only scientific facts but also societal values and narratives determine how a society acts and how it incorporates scientific knowledge in its course of action. GSS therefore embraces policy formulation and implementation as a design process where input from science (models and data) is only one of the pertinent factors. Policy takes place in the context of societal values and narratives of what is required, what constraints there are, why possible solutions will or will not work, and why it is 'right' to apply selected or alternative policies. In this context, GSS embraces social media and online platforms as forums for discussion and even considers art as a means of communication and coordination between science, technology, policy makers and citizens.

In democracies the policy makers are the elected politicians supported by technical officers and other officials. There are also unelected policy makers, including the officials of the E.C. and The World Bank. However, in many countries there is a widening disconnect between citizens and those who govern. Citizen engagement is an essential element in Global Systems Science. It means that both 
policy makers and scientists have to enable and facilitate citizens being active in the policy making process and policy implementation.

Global Systems Science has four elements:

- policy-driven questions, policy formulation and implementation, and narratives

- the interdisciplinary science of complex systems supporting policy

- policy informatics - tools and data to investigate and visualise policy outcomes

- coordinating citizen engagement in the policy process.

In this chapter it will be shown how these elements work together to make science operational for policy formulation and evaluation by policy makers and citizens.

\section{Examples of Global Systems}

The term 'global' suggests that the science of global systems is restricted to phenomena at a global scale. In fact what it means is that for some systems the micro- and meso-level dynamics affect and are affected by the dynamics at the global scale. Thus Global Systems Science applies to policy questions at all levels from the local to the global. The following examples will illustrate this.

\subsection{Epidemiology}

Individual to individual infection drives epidemics at the microlevel, with disease passed from one infected person to other susceptible non-infected people [20]. Settlements such as villages enable disease to spread at the microlevel. Towns and cities enable diseases to spread at the mesolevel. Transportation, especially air transportation, enables disease to spread at the global level [10]. Health policy is made at all scales. At the global level the World Health Organisation's operational role in emergencies includes leading and coordinating the health response in support of countries, undertaking risk assessments, identifying priorities and setting strategies, providing critical technical guidance, supplies and financial resources as well as monitoring the health situation [41]. At the national scale, governments have committees that assess and set policies to contain epidemics. At the microlevel individuals may self-quarantine, self medicate or avoid people with symptoms of disease. Despite the complexity of epidemics, this is an area where complex systems science has been very successful $[6,12,35]$. 


\subsection{Finance}

The financial crash of 2008 showed that economic failure could rapidly cascade across institutions and national boundaries, and that banking and finance are global systems. Financial systems today have complicated networks of claims and obligations linking the balance sheets of organisations such as banks and hedge funds. Sophisticated financial products further increase the complexity. These interdependencies enable amplifying positive feedback where problems in the financial system can snowball and make things worse $[8,9,11,17]$.

Some multinational companies arrange their affairs to exploit the regulations between individual countries to minimise what they pay in tax, sometimes with governments gaming each other [30]. Taxation and tax avoidance are global systems: 'Tax fraud and tax evasion affects us all. It occurs within a country and across countries both within the EU and globally. That is why a single country cannot solve the problem on its own. The EU and Member States need to work more together and internationally to combat the problem at home and abroad' [15]. Taxation is a global system but, ultimately, tax avoidance at the global scale transfers wealth from individual people to individual people at the microlevel.

Beyond this, actors in finance do not act as predicted by the classical theory of economics. They are neither perfectly informed (as acknowledged now by economic theories of limited information) nor do they act 'rationally' in the strict sense of the word [32]. Actors in financial markets are driven by narratives and by collective behaviour (e.g. herding behaviour as the origin of financial crashes) [31]. The behaviour of actors in financial systems is influenced as much by networks as it is with them acting as individuals trying to make rational decisions [33].

\subsection{Cities}

Cities are systems at a global mesolevel. Top down the mayor of a city manages the many subsystems that impinge on the lives of citizens at the microlevel. Bottom-up the mayor sees the city in an ecology of other cities competing and collaborating at national and international levels. e.g. competing for business, tourism, and even the Olympic Games. Complex systems science already contributes to our understanding of city dynamics, e.g. through new simulation-based land use and transportation models [5]. Also statistical studies show that as city size increases the number of petrol stations per capita decreases, as do the lengths of roads, electricity lines, and other infrastructure. In contrast to 'sub-linear scaling', some social phenomena have 'super-linear scaling' e.g., the average wage increases with city size, as do crime, cases of aids and flu, the number of patents, and many other variables [40]. 


\subsection{The Internet}

The Internet exemplifies the 'very local—completely global' nature of global systems. At the local level there are billions of individual users accessing and interacting with the global resource of billions of web pages. There are many intermediate level structures such as companies, organisations, service providers, the Cloud, and governments. Despite its complexity and importance, the Internet was not designed top-down and no-one owns or controls all of it [29]. The Internet enables many global structures to function including finance and cities. It has supported revolutionary changes in social behaviour at the individual and group levels. These range from intense personal interaction through Facebook, to online shopping, online banking, and interactions with government agencies. The Internet makes Big Data accessible and supports an explosion in communications. It is one of the enablers of Global Systems Science.

\subsection{Climate Change}

The 'Anthroprocene' is the global system. The physical behaviour of the oceans and atmosphere is impacted on and impacts on human behaviour at every level, from the hurricanes that rage across international borders to individuals abandoning their flooded houses. The Anthropocene is a geological epoch in which humans have become a dominant driver of Earth System change. It reflects the nature, scale and magnitude of human impacts on the Earth [3]. One of the impacts of human activity is irreversible climate change [38]. The climate is one aspect of a very large very complex multilevel system. It has physical subsystems such as the oceans and the atmosphere, and it has social systems including health, finance, cities, transportation, and policy making. It took many years to get international agreement on the target of the '2 degree goal' signed in Paris in 2015 [13, 39], and it may take many more for this to result in definitive action. A related problem is the unsustainable consumption of the Earth's resources, currently running at 1.6 planets, i.e. it takes the Earth 1 year and 6 months to regenerate what we use in a year [18].

\section{Narratives in Global Systems Science and Policy}

'Narratives provide the structure by which individuals understand the world, in which they live. They tell individuals which elements and processes are related to each other, how to structure their experience, how to evaluate the other individuals, objects and processes. By knowing their role in narratives individuals know how to behave. Narratives also tell individuals how others are likely to behave. Narratives lead to actions and they thus causally linked to behaviours. ... Narratives exist at all 
levels of social reality: micro, meso, and macro....the power to edit and control narratives is an important source of control in social processes' [31].

Although policy makers may be committed to evidence-based policy, scientific evidence and theory frequently gets swept up in the evolving narratives of policy. A popular narrative to counter unwelcome scientific evidence and theories is that scientists exaggerate or even falsify their results because they want the next tranche of funding - and sometimes they do!

Irrespective of what scientists say and do, the narratives of policy are evolving all the time. For example, in the UK the narrative of loss of sovereignty to Brussels has been a powerful narrative for decades resulting in the referendum to leave the European Union on 23rd June 2016. Recently this narrative has a potent variant that Britain is being swamped by welfare tourist immigrants from Europe filling its hospitals and taking all the social housing. This narrative may result in a vote for a 'Brexit', despite the counter narrative that European immigrants make a positive contribution to the British economy including staffing its hospitals. Another narrative, supported by most economists claims that the UK will suffer financially if it leaves Europe. This is countered by the narrative that economists are always wrong in their forecasts so that their prognostications are actually strong evidence that the UK will not be harmed economically by the Brexit. At the time of writing, with a few weeks to go before the referendum, the polls show almost equal support for leaving or staying, and that the contradictory narratives of each side are much more influential than science.

To be effective Global Systems Science must understand how the science of complex systems can make a contribution to policy when the logic that drives narratives is not the logic of the scientific process. This will be discussed in Sect. 8 .

\section{Prediction and Policy}

The question as to whether or not a policy will have the desired outcomes involves some kind of prediction. However, for many reasons the concept of prediction that has developed in the traditional sciences is not applicable to social systems.

\subsection{Point prediction}

A point prediction says that a system will be in a particular state at a particular point of time in the future, e.g. the laws of physics predict that $1 \mathrm{~s}$ after dropping a pebble over a cliff it will have fallen $4.9 \mathrm{~m}$. In contrast, when systems have sensitive dependence on initial conditions, even a perfect model is unable to predict its long term behaviour. In a classic paper on the weather, Lorenz writes "two states differing by imperceptible amounts may eventually evolve into two considerably different states. If, then, there is any error whatever in observing the present state- 
and in any real system such errors seem inevitable - an acceptable prediction of an instantaneous state in the distant future may well be impossible" [27]. Sensitivity to initial conditions makes point-prediction of long term weather impossible. The best that can be done is identifying the likelihood of weather events in space and time.

\subsection{Extreme Events}

Conventional science makes predictions by extrapolating the past into the future. For example, the laws of physics are based on observations of the past and the assumption that the underlying phenomenology will persist into the future. Although physical science gives many examples of excellent predictions, there are areas where it does not, e.g. earthquakes and other extreme events. Extreme events are characterised by them never having happened before, or happening very rarely, e.g. the 2005 levee failure in New Orleans caused by Hurricane Katrina and a unique combination of design errors, maintenance failures and weather conditions [1]. The financial crash of 2008 was another extreme event, caused in part by new kinds of financial instrument, new kinds of relationship between regulators and financiers, and unknown network structures. Social systems may be predictable when they are behaving 'normally' but cease to be predictable when 'normal' regimes transition to new kinds of behaviour, possibly never seen before.

\subsection{Unintended Consequences}

European and US biofuel policy provides an example of policy in one subsystem having unintended and undesirable consequences in another subsystem. Motivated by reducing greenhouse gases, polices encouraging the use of biofuels have led to starvation in poor regions of the world as farmers switched from providing food for local people to biofuels for an international market. Here the polices for the European and US Transportation, Energy and Environmental subsystems had an impact on the African and Latin American Food production subsystems, described by the UN special rapporteur as a 'crime against humanity' [25]. As this example shows, apart from believing that a proposed policy will give the desired outcomes, policymakers need to know about possible unintended consequences. This is a systems question: will intervention in one subsystem have consequences in another.

\subsection{Definitive Predictions are Impossible in Social Systems}

Like the weather, the long term behaviour of social systems is also impossible to predict. Not only are many social systems sensitive to initial conditions, but the 
equations governing their behaviour are not known. For example, there is no formula that can guarantee your stock market investments will appreciate, there is no formula that can point-predict patterns of migration.

\subsection{Exploring the Future}

Although it is impossible to say definitively what will happen in social systems, it is possible to say what might happen and how likely it is. Conviction politicians assert that their policy will have one outcome with a $100 \%$ certainty. In contrast Global Systems Science may show that a policy could have one of a number of outcomes and indicate how likely each is. It does this by taking a systems approach to representing the world and how it changes [34]. This enables policy makers to explore possible futures and base their decisions on the best evidence available.

\section{Systems, Complexity and Prediction for Policy}

\subsection{Systems}

Systems theory is founded on the principle that the behaviour of a system emerges from the interactions between the components of the system. A system is defined as (1) an assembly of components, connected together in an organised way; where (2) the components are affected by being in the system and the behaviour of the systems is changed if they leave it; (3) the organised assembly of components does something; and (4) the assembly has been identified as being of particular interest. In policy the objectives determine what is of particular interest. The systems approach then asks what things can affect the desired outcome, what things can affect those things, and so on. This establishes the components of the system and their interactions [24]. The state of a system is a snapshot of it in time. A series of snapshots give a trajectory. Science attempts to reconstruct the phenomenology underlying observed trajectories so that given the state of a system at one time it can determine the state of the system at a future time. The systems approach includes using diagrams representing the state of the components as annotated boxes and the effects of one component on another as annotated arrows.

System diagrams give an overview of how a system might behave, e.g. they may show there are feedback loops where the system can spiral out of control. They can be used to support qualitative reasoning about behaviours, as in Checkland's soft systems. Forester's systems dynamics quantifies the variables associated with the boxes and mathematical functions with the arrows. This enables the state of each component at one 'tick of the clock' to be calculated from the state of the components at the previous 'tick of the clock'. Repeating this process gives a 
computer simulation of the evolving states of the system through time. This allows exploration of the consequences of changing the system parameters on possible system futures. This approach was used in the controversial Limits to growth study [28] whose critics misunderstood the purpose which was to investigate possible futures rather than predict any particular future. System dynamics is an important step towards understanding the possible behaviour of complex social systems [24].

\subsection{Complexity}

There is no consensus on the definition of the word 'complex', but wide agreement that complexity can arise when one or more of the following apply:

- many heterogeneous parts, e.g. a city, a company, the climate, markets, riots

- sensitive dependence on initial conditions, e.g. weather systems, investments

- path-dependent dynamics, e.g. evolution, elections, personalities, famine, war

- network connectivities and feedback, e.g. gossip, epidemics, banker networks

- dynamics emerge from interactions of autonomous agents, e.g. traffic, markets

- self-organisation into new structures and behaviours, e.g. ghetto formation

- co-evolving subsystems, e.g. land-use and transport, virus software, design

- globality and multilevel dynamics, e.g. companies, the Internet, revolutions

- confounding behaviour and reflexivity, e.g. disobedience, contrarianism

- unrepeatable experiments, e.g. electing a government, war, having children

Most social systems exhibit some or all of these characteristics. Any one of them can make systems appear complex, but together they can make systems very difficult to understand, predict, control, and manage.

\subsection{The Integrative Science of Complex Systems}

Conventional science is compartmentalised into domains such as physics, chemistry, biology, psychology, sociology, and so on. Some scientists specialise in a single domain, knowing every aspect of it, drilling down to great depth in research. In contrast to this in-depth vertical science, complex systems science involves horizontal concepts and integrative research across the domains, as illustrated in Fig. 1. It is interdisciplinary and usually involves teams with complementary specialisms. This interdisciplinarity of complex systems science is essential for policy [19]. 


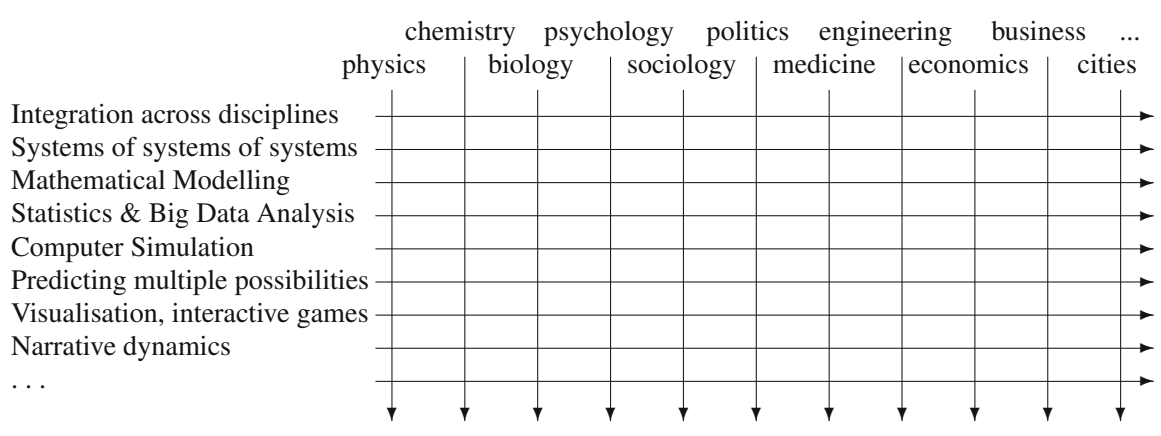

Fig. 1 Complex systems science horizontally integrates in-depth individual scientific domains

\section{Policy Informatics: Tools for Exploring the Future}

In making science available to policy makers and citizens the methods of Global Systems Science must be embodied in user-friendly computational systems created not by the policy makers but by scientists and professional software providers. In some areas this is already happening. For example, Geographical Information Systems have been used in the public and private sectors for years.

\subsection{Data for Policy}

Data is an essential part of the information systems needed to support policy. Most countries make their census and other population data available online, with or without charge, and these are the basic data for policy. In recent years completely new sources of data have emerged through telecommunications, social media, ecommerce, and so on. These 'big data' are being extensively researched by the complex systems and computational social science communities and new policyoriented analytics are emerging.

\subsection{Agent-Based Modelling for Policy Exploration}

For most policy questions, where there are no formulae to predict future behaviour of the whole system, Agent Based Models allow future behaviours to be investigated by computer simulation. The idea is that agents such as people or companies are represented inside computers and their interactions are simulated through time [4]. For example, consider drivers as agents on a crowded road. Each driver adjusts their speed and direction according to nearby vehicles. Given this information at one tick of the clock later it is possible to model the drivers' speed and direction 
at the next tick of the clock when they are all in slightly different positions. In this way the behaviour of all the traffic emerges, including the 'shock waves' often experienced on long crowded roads when the traffic suddenly slows down or stops for no apparent reason [5]. Agent Based Models (ABM) are also called MultiAgents Systems (MAS).

ABMs can be powerful tools for examining the behaviour of social systems. Following initialisation, all the interactions can be computed to find the state at the next tick of the clock, and so the evolution of the system can be simulated into the future. The dynamics of many social systems are sensitive to initial conditions and similar initial conditions may lead to very different outcomes. For this reason, simulations are run for many sets of initial conditions to give distributions of outcomes. When simulations are run for thousands or millions of sets of initial conditions scientists can probe the space of possible futures. Sometimes these policy-induced futures all look the same, and a policy maker can be confident of the outcome. Sometimes the policy-induced futures can vary considerably, giving the policy maker an insight into the possible outcomes of policy. If some of these outcomes are very bad the policy maker may decide that the possible benefits do not outweigh the risks.

\subsection{Synthetic Micropopulations}

The behaviour of many social systems requires that they be modelled at the level of individual people. Apart from census data, usually collected every decade, there are very few surveys of everyone in a community. The idea behind creating synthetic micropopulations is that aggregate data can be disaggregated to the microlevel with the same statistical distributions as the original data. The first synthetic micropopulations were created for modelling road traffic and air pollution by Barrett and his team at Los Alamos National Laboratory in the nineteen nineties [5, 7]. There are now synthetic micropopulations for the whole of the USA, and the CoeGSS project recently funded by the European Commission will build a synthetic population for the whole of Europe [16].

\subsection{Visualisation and Visual Analytics}

Visualisation is important in policy informatics since it enables lay people to see otherwise hidden patterns of system behaviour, e.g. animations provide a powerful way of understanding system behaviour, and simulations often provide ideal data streams for this. Visual analytics goes beyond this, using graphical interfaces to support analysis and reasoning about systems. It combines visualisation, human perception and cognition, data management, data mining and spatio-temporal data analysis [26]. 
Fig. 2 Citizens in the policy loop

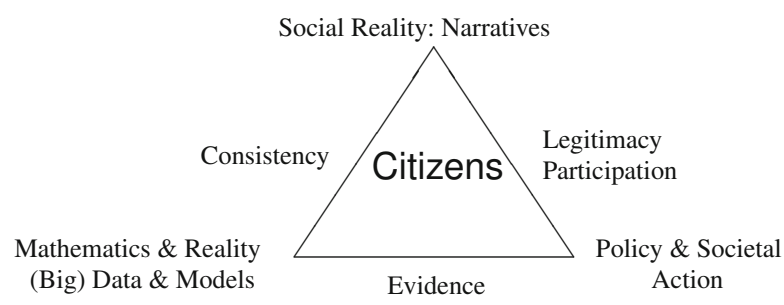

\section{Citizens in the Policy Loop}

Figure 2 shows citizens at the centre of social reality and narratives, data and models, and policy and societal action. Traditional science often assumes that it studies objective phenomena, but social reality is constructed in interactions between individuals, and these social interactions are necessary to sustain the social reality. Social constructs are the results of human decisions rather than objective reality, and narratives are a way to navigate and construct reality $[2,31]$.

Human behaviour is reflexive and people can respond to predictions by making them self-fulfilling prophesies or deliberately falsifying them, e.g. predicting a food shortage can cause panic buying resulting in a food shortage, while predicting that a candidate will win an election can make voters switch resulting in them losing. Also, some people are contrarian-predict that they will do one thing and they will do another. Thus policy cannot act on people, it has to act with people. Social media have given narrative power to everybody and thereby decoupled it from authority, e.g. the Twitter revolution during the Arab Spring, political campaigns on Facebook, and bloggers as opinion makers. The Arab Spring showed that people power can topple regimes but this is the beginning rather than the end of a process[36].

\section{GSS Coordinating Policy Makers, Citizens and Scientists}

Citizen engagement requires policy makers to actively bring lay people into the policy making process, and evidence based policy requires policy makers to bring scientists into the policy making process. Thus the policy making process requires coordination between policy makers, citizens and scientists. How can this work?

\subsection{Policy Design}

Like any artefact, policies are designed [21,23]. The design process begins with a perceived problem, need, or desire, and proceeds by generating and evaluating possible solutions. A good solution is rarely found immediately and there are more 
iterations around the generate-evaluate cycle. Unlike other approaches to problem solving, it is common during design to discover that no acceptable solutions can be found, and the requirements or constraints must be changed. But this changes the problem! Thus the design process is a coevolution between the problem and its solution and ends when a satisfactory problem-solution pair is found.

Policy seeks to achieve the 'best' outcome, but in design there is rarely an absolute best or 'optimum'. Herbert Simon called finding an acceptable compromise between competing heterogeneous dimensions satisficing [37]. Policy invariably involves satisficing rather than optimising.

\subsection{The GSS Policy Process}

Figure 3 shows how scientists work with policy makers and citizens within the GSS policy framework as a policy team. In the context of the prevailing narratives, on the left citizens and politicians decide how the world ought to be. After establishing the policy objectives and constraints, there is the creative policy generate-evaluate cycle shown at the centre of the diagram. This is where science can inform policy, using the tools of policy informatics shown at the centre of the cycle to create policy options and evaluate them.

Ideally a policy emerges from this process that satisfices the requirements and constraints. If not the objectives and constraints must be revisited. For example, the policy makers may decide that the budget can be increased, or it may accepted that one of the cherished objectives is not attainable. Thus the policy problem has changed and the policy team begins generate-evaluate cycle again. On finding what they think is an acceptable policy the policy team presents their plan for ratification by the elected politicians and citizens. If it is rejected the policy team must go back

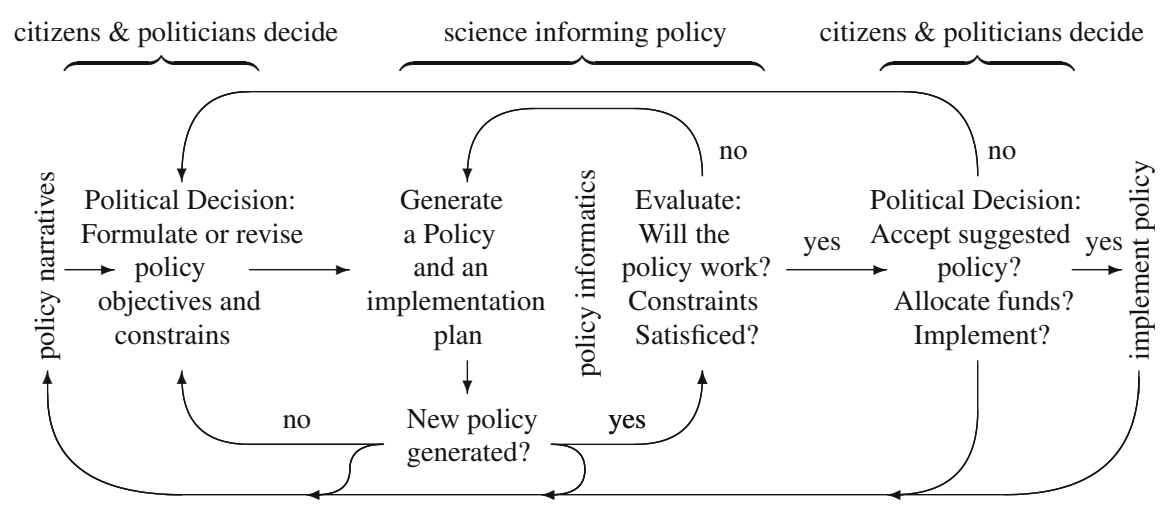

Fig. 3 Science informing policy within the Global Systems Science policy making process 
to the generate-evaluate phase or even to phase of formulating the objectives and constraints.

The evolving policy narrative is shown at the left and bottom of Fig. 3. Policy objectives and constraints emerge from the prevailing narratives of how the world ought to be. Those narratives evolve while new policies are being designed. The generate-evaluate cycle at the heart of science-informed policy design is more a spiral through time than a cycle closing on itself. New information is constantly being collected, hypotheses are constantly be tested, and new information is constantly being accumulated. Whether or not feasible polices are generated or implemented this new information feeds new and evolving narratives, possibly changing the policy objectives and constraints. In evidence-based policy narrative dynamics fill any factual gaps, both removing and creating uncertainty. GSS has the challenge of creating theories of the dynamics of multilevel narrative dynamics [22].

As Fig. 3 shows, in Global Systems Science the decision-making process of policy formulation and implementation is firmly in the hands of citizens and politicians. Science makes its contribution by helping to generate and evaluate policies and providing the best possible evidence-based answers to the questions of how can policymakers be sure that their policies will have the desired outcomes and not have undesirable outcomes.

\section{Conclusion}

Global Systems Science has been presented as the combination of:

- policy-driven questions, policy formulation and implementation, and narratives

- the interdisciplinary science of complex systems supporting policy

- policy informatics-tools and data to investigate and visualise policy outcomes

- coordinating citizen engagement in the policy process.

GSS provides a methodology for applying the science of complex systems in policy making with citizen engagement. The rules of the game are that politicians and citizens establish how the world ought to be, and that scientists help them discover how the would could or could not be in the policy design process of generating and testing policy options. Scientists do this by the creation of computer tools usable by lay people, and making the output of those tools accessible to everyone as part of the policy team.

Acknowledgements R. Dum is with The European Commission, and Jeffrey Johnson (jeff. johnson@open.ac.uk) is with The Open University and the UNESCO UniTwin Complex Systems Digital Campus (CS-DC). This work is an outcome of the Non-Equilibrium Social Science (NESS) Project supported by the Future and Emerging Technologies (FET) division of the European Commission. A free online course on Global Systems Science and Policy aimed at policy makers, scientists and citizens is presented periodically by the CS-DC at www.futurelearn.com/courses/globalsystems-science. 
Open Access This chapter is distributed under the terms of the Creative Commons Attribution 4.0 International License (http://creativecommons.org/licenses/by/4.0/), which permits use, duplication, adaptation, distribution and reproduction in any medium or format, as long as you give appropriate credit to the original author(s) and the source, provide a link to the Creative Commons license and indicate if changes were made.

The images or other third party material in this chapter are included in the work's Creative Commons license, unless indicated otherwise in the credit line; if such material is not included in the work's Creative Commons license and the respective action is not permitted by statutory regulation, users will need to obtain permission from the license holder to duplicate, adapt or reproduce the material.

\section{References}

1. Andersen, C., et al.: The New Orleans hurricane protection systems: what went wrong and why? A Report by the American Society of Civil Engineers Hurricane Katrina External Review Panel (Reston) (2007). ISBN-13:978-0-7844-0893-3

2. Anzola, D., Johnson, P. G., Salgado, M., Gilbert, N.: Sociology and non-equilibrium social science. In: Johnson, J., Nowak, A., Ormerod, P., Rosewell, B., Zhang, Y.-C. (eds.) NonEquilibrium Social Science and Policy. Springer, Berlin (2016)

3. Bai, X., van der Leeuw, S., O’Brien, K., Berkhout, F., Biermann, F., Brondizio, E. S., Cudennec, C., Dearing, J., Duraiappah, A., Glaser, M., Revkin, A., Steffen, W., Syvitski, J.: Plausible and desirable futures in the Anthropocene: a new research agenda. Glob. Environ. Chang. (2015). http://www.sciencedirect.com/science/article/pii/S0959378015300546

4. Bandini, S., Manzoni, S., Vizzari, G.: Agent based modeling and simulation: an informatics perspective. J. Artif. Soc. Soc. Simul. 12(4) (2009). http://jasss.soc.surrey.ac.uk/12/4/4.html

5. Barrett, C., Beckman, R., Berkbigler, K., Bisset, K., Bush, B., Campbell, K., Eubank, S., Henson, K., Hurford, J., Kubicek, D., Marathe, M., Romero, P., Smith, J., Smith, L., Speckman, P., Stretz, P., Thayer, G., Eeckhout, E., Williams, M.D.: TRANSIMS: transportation analysis simulation system. Los Alamos National Laboratory Unclassified Report, Tech. Rep. LA-UR00-1725 (2010)

6. Barrett, C., Bisset, K., Leidig, J., Marathe, A., Marathe, M.: An integrated modeling environment to study the coevolution of networks, individual behavior, and epidemics. AI Mag. 31(1), 75-87 (2010)

7. Barret, C.J., Eubanks, S., Marathe, A., Marathe, M.V., Pan, Z., Swarup, S.: Information integration to support model-based policy informatics. Innov. J. Public Sect. Innov. J. 16(1), Article 2 (2011)

8. Buchanan, M.: Economics: meltdown modelling. Could agent-based computer models prevent another financial crisis? Nature 460, 680-682 (2009). http://www.nature.com/news/2009/ 090805/full/460680a.html

9. Buchanan, M.: Physics in finance: trading at the speed of light. Nature 518, 11 February 2015. http://www.nature.com/news/physics-in-finance-trading-at-the-speed-of-light- 1.16872

10. Colizza, V., Barrat, A., Barthélemy, M., Vespignani, A.: The role of the airline transportation network in the prediction and predictability of global epidemics. Proc. Nat. Acad. Sci. 103(7), 2015-20120 (2015)

11. Delli Gatti, D., Gallegati, M., Greenwald, B., Russo, A., Stiglitz, J.E.: The financial accelerator in an evolving credit network. J. Econ. Dyn. Control 34(2010), 1627-1650 (2010)

12. Eubank, S., Guclu, H., Kumar, V.S.A., Marathe, M.V., Srinivasan, A., Toroczkai, Z., Wang, N.: Modelling disease outbreaks in realistic urban social networks. Lett. Nat. 429, 180-184 (2004). http://ndssl.vbi.vt.edu/Publications/modellingDisease.pdf

13. European Commission: Climate action: The 2015 International Agreement (2015). http://www. cop21.gouv.fr/en/195-countries-adopt-the-first-universal-climate-agreement/ 
14. European Commission: Global System Science (2016). https://ec.europa.eu/digital-singlemarket/en/global-systems-science

15. European Commission: The fight against tax fraud and tax evasion (2016). http://ec.europa.eu/ taxation_customs/taxation/tax_fraud_evasion/index_en.htm

16. European Commission: CoeGSS: a new high performance computing centre of excellence for global systems science is Born (2016). https://ec.europa.eu/digital-single-market/en/news/ coegss-new-high-performance-computing-centre-excellence-global-systems-science-born

17. Gai, P., Kapadia, S.: Contagion in financial networks. Working Paper No. 383, Publications Group, Bank of England, London (2010). http://www.bankofengland.co.uk/research/ Documents/workingpapers/2010/wp383.pdf

18. Global Footprint Network: World footprint: do we fit on the planet? (2016). http://www. footprintnetwork.org/en/index.php/GFN/page/world_footprint/

19. Helbing, D.: Globally networked risks and how to respond. Nature 497(7447), 51-59 (2013)

20. Hethcote, H.W.: The mathematics of infectious diseases. SIAM Rev. Soc. Ind. Appl. Math. 42(4), 599-653 (2000). http://leonidzhukov.net/hse/2014/socialnetworks/papers/ 2000SiamRev.pdf

21. Johnson, J.: Policy design, planning and management in global systems science. In: Card, M.-A., Krob, D., Lui, P.C., Tan, Y.H., Woord, K. (eds.) Complex Systems, Design and Management. Springer, Heidelberg (2014)

22. Johnson, J.H.: Hypernetworks: multidimensional relationships in multilevel systems. Eur. Phys. J. Spec. Top. 225(5), 214 (2016)

23. Johnson, J.H., Cook, M.: Policy design. In: Aiguier, M., et al. (eds.) Complex Systems, Design and Management. Springer, Heidelberg (2014)

24. Johnson, J., Fortune, J., Bromley, J.: Systems, networks and policy. In: Johnson, J., Nowak, A., Ormerod, P., Rosewell, B., Zhang, Y.-C. (eds.) Non-Equilibrium Social Science and Policy. Springer, Berlin (2016)

25. Kleier, K.: The backlash against biofuels. Nat. Rep. Clim. Chang. 2, $9-11$ (2008). http://www. nature.com/climate/2008/0801/pdf/climate.2007.71.pdf

26. Keim, D., Kohlhammer, J., Ellis, G., Mansmann, F., (eds.): Mastering the information age solving problems with visual analytics. Published by the Eurographics Association (2010). ISBN 978-3-905673-77-7. http://diglib.eg.org

27. Lorenz, E.N.: Deterministic nonperioidic flow. J. Atmos. Sci. 20, 130-141 (1963)

28. Meadows, D.H., Meadows, D.L., Randers, J., Brehens, W.W.: The Limits to Growth. Universe Books, New York (1972)

29. Muller, M.: Who owns the Internet? Ownership as a legal basis for American control of the Internet. Fordham Intellect. Prop. Media Entertain. Law J. 15(3), 2005 Article 2 Volume XV Book 3. The Berkeley Electronic Press (2005). http://ir.lawnet.fordham.edu/cgi/viewcontent. cgi?article $=1310 \&$ context $=$ iplj

30. Needham, C.: Corporate tax avoidance by multinational firms. Library of the European Parliament, 23 Sept 2013 (2013). http://www.europarl.europa.eu/RegData/bibliotheque/briefing/ 2013/130574/LDM_BRI(2013)130574_REV1_EN.pdf

31. Nowak, A., Kacprzyk-Murawska, M., Serwotka, E.: Social psychology and the narrative economy. In: Johnson, J., Nowak, A., Ormerod, P., Rosewell, B., Zhang, Y.-C. (eds.) NonEquilibrium Social Science and Policy. Springer, Berlin (2016)

32. Ormerod, P.: Economics. In: Johnson, J., Nowak, A., Ormerod, P., Rosewell, B., Zhang, Y.-C. (eds.) Non-Equilibrium Social Science and Policy, Springer, Berlin (2016)

33. Ormerod, P.: Positive Linking. Faber and Faber, London (2012)

34. Ostrom, E.: Governing the Commons: The Evolution of Institutions for Collective Action. Cambridge University Press, Cambridge (1990)

35. Pastor-Satorras, R., Castellano, C., Van Mieghem, P., Vespignani, A.: Epidemic processes in complex networks. Rev. Modern Phys. 87, 925 (2015). http://arxiv.org/pdf/1408.2701.pdf

36. Roberts, A.: The Arab spring: why did things go so badly wrong? The Guardian Newspaper, 15 Jan 2016 (2016). http://www.theguardian.com/commentisfree/2016/jan/15/arab-spring-badlywrong-five-years-on-people-power 
37. Simon, H.: The Sciences of the Artificial. MIT Press, Cambridge, MA (1965)

38. Stern, N.: The Stern Review: The Economics of Climate Change. Cambridge University Press, Cambridge (2006)

39. United Nations Climate Change Conference: 195 countries adopt the first universal climate change agreement (2015). http://www.cop21.gouv.fr/en/195-countries-adopt-the-firstuniversal-climate-agreement/

40. West, G.: The surprising math of cities and corporations. Ted Talks, July 2011. (2011). https:// www.ted.com/talks/geoffrey_west_the_surprising_math_of_cities_and_corporations

41. World Health Organisation: WHO, What We Do (2015). http://www.who.int/about/what-wedo/en/ 